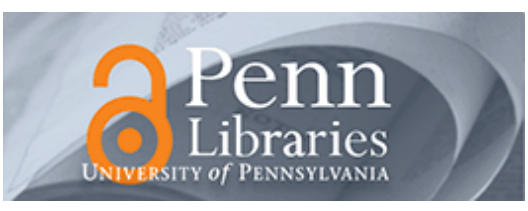

University of Pennsylvania ScholarlyCommons

2004

\title{
What Happens When Information Leaves a Market? Evidence From Postbankruptcy Consumers
}

David K. Musto

University of Pennsylvania

Follow this and additional works at: http://repository.upenn.edu/fnce_papers

Part of the Finance and Financial Management Commons

\section{Recommended Citation}

Musto, D. K. (2004). What Happens When Information Leaves a Market? Evidence From Postbankruptcy Consumers. The Journal of Business, 77 (4), 725-748. http://dx.doi.org/10.1086/422437 


\title{
What Happens When Information Leaves a Market? Evidence From Postbankruptcy Consumers
}

\begin{abstract}
Federal law mandates the removal of personal bankruptcies from credit reports after 10 years. The removal's effect is market efficiency in reverse. The short-term effect is a spurious boost in apparent creditworthiness, especially for the more creditworthy bankrupts, delivering a substantial increase in both credit scores and the number and aggregate limit of bank cards. The longer-term effect is lower scores and higher delinquency than initial full-information scores predict. These findings relate to both the debate over the bankruptcy code and the wisdom of influencing market clearing by removing information.
\end{abstract}

\section{Disciplines}

Finance and Financial Management 


\section{What Happens When Information Leaves a Market? Evidence from Postbankruptcy Consumers*}

\section{Introduction}

Consumers finance corporations, and corporations finance consumers. A long literature explores many dimensions of the former, but it is not clear how much of this analysis applies to the latter. The magnitudes are reversed; instead of the hundreds of millions of consumers choosing among thousands of corporations, we have thousands of corporations choosing among hundreds of millions of consumers. The idea that consumers invest as if they know approximately what there is to know about corporations seems unlikely to apply so well in the other direction. The credit bureaus that have emerged to gather and sell consumer-specific information face both the difficulty of gathering the relevant facts and federal limits on what they can sell. These limits

* A previous version of this article was circulated under the title "The Effect of Personal Bankruptcy on Credit Access: Evidence from a Panel Database of Credit Reports." I am grateful to Andy Abel, Larry Ausubel, Peter Burns, Bill Dupor, Hulya Eraslan, Gary Gorton, Bob Hunt, Tony Santomero, Nick Souleles, Robert Tsou, Amir Yaron, seminar participants at the Federal Reserve Bank of Philadelphia, McGill, Temple, USC and Wharton, representatives of several bank-card issuers, two referees, and Anil Kashyap, the editor, for helpful comments and suggestions, and Charles Chung, William Loo, and Angela Arriaza of Experian for providing, organizing, and discussing the database. Financial support from the Wharton Financial Institutions Center and research assistance from Lily Fang, Nadia Masri, Dan Mingelgrin, and Adriana Riviere-Badell are gratefully acknowledged. Contact the author at musto@wharton. upenn.edu.

(Journal of Business, 2004, vol. 77, no. 4)

(C) 2004 by The University of Chicago. All rights reserved. 0031-8248/2004/7704-0004\$10.00
Federal law mandates the removal of personal bankruptcies from credit reports after 10 years. The removal's effect is market efficiency in reverse. The short-term effect is a spurious boost in apparent creditworthiness, especially for the more creditworthy bankrupts, delivering a substantial increase in both credit scores and the number and aggregate limit of bank cards. The longerterm effect is lower scores and higher delinquency than initial full-information scores predict. These findings relate to both the debate over the bankruptcy code and the wisdom of influencing market clearing by removing information. 
are attempts to influence the clearing of the consumer-credit market, and it is an open empirical question what they actually accomplish. This article considers one of the intuitively most-important limits, the 10 -year limit on reporting personal bankruptcy, analyzing its immediate effect on credit access and its longer-run effect on creditworthiness. The findings relate to both the debate over the bankruptcy code and the wisdom of influencing market clearing by removing information.

One way to describe this study is as a test for market efficiency in reverse. When a market adds new information about an issuer, there is a short-run effect on the clearing price and quantity of its securities, and a long-run effect that this change in its financing opportunity set has on its operations, presumably in the direction of economic efficiency. Were the market to subtract information, there would be a short-run effect on clearing and a longer-run effect, but this time away from informational and economic efficiency. To the extent that consumer creditors rely on credit bureaus for information, the reporting limit subtracts adverse information from the market, implying both a spurious short-term boost to apparent creditworthiness, and whatever credit access that brings, and the longer-term effect on the consumer's behavior of getting this access. Alternatively, if lenders have other means of gaining the information represented by the bankruptcy information, removing the flag should have little effect. Therefore, the results bear on the informational efficiency of the consumer credit market, the efficacy of regulating this market with reporting limits, and the quality of postbankruptcy credit access, which in turn bears on the incentive to file in the first place.

What makes the analysis feasible is a pair of panel databases of credit reports from one of the major credit bureaus, Experian. One tracks 44,000 consumers with indicators of past Chapter 7 bankruptcies filings, that is, "bankruptcy flags," on their July 1994 (7/94) credit reports, over nine dates: quarterly from 7/94 to 4/96, and 9/97. It also covers 20,000 consumers without bankruptcy flags on 7/94. The other tracks 100,000 randomly sampled consumers monthly from 3/97 to $3 / 00$, and it provides some demographic information. Each report contains hundreds of statistics on credit availability and usage, so the opportunity to analyze consumer credit dynamics, particularly as they relate to Chapter 7 , is substantial.

The data cover a variety of credit types, but the analysis focuses on bank-card credit, for three reasons. First, bank-card credit is generally unsecured, and the major part of unsecured consumer credit, so it is the major market affected by creditworthiness issues. Second, the industry's intense solicitation is a fast link between potential and actual bank-card access. A consumer whose credit report changes in a way that frees up bank-card credit will soon have it, and his credit report will soon show it. By contrast, credit relationships such as car loans 
reflect credit-report changes only when the consumer actively shops for them. And, finally, the typical bank-card lender originates millions of small loans, which implies a dependence on credit bureaus and therefore exposure to the information limits imposed on credit bureaus.

Measuring the short-term boost is easy because both panels track a group of filers past the moment when their flags disappear. By comparing a consumer with a flag to that person a year later, without a flag, we observe the effect of just the flag and the passage of a year, controlling for personal circumstances, including those that precipitated the filing. That is, the flag's departure, unlike its arrival, reflects a preset legal schedule and so is exogenous to the consumer's circumstances. To control for the passage of a year, so as to focus more precisely on the effect of the flag's removal, the same year-later comparison is conducted on past filers who do not lose their flags, so that the removal's short-term effect is apparent in the difference between the first group and the others. Measuring the long-term effect is constrained by the data to a couple years, as both panels track only a few filers past 12 years post-filing. What we can do is follow a group of filers from their initial state with bankruptcy flags to the end of the data and ask how their creditworthiness at the end compares to their creditworthiness at the beginning.

The results on the short-term effect show a strong effect for the most creditworthy past filers. Those whose credit scores before the flag removal put them in the fortieth to fiftieth percentiles of the general population, high for a past filer, experience a leap in credit scores past $19 \%$ of the general population, on average, and an $\$ 1800$ average lift in bank-card credit limits. The effect shrinks as the cum-flag credit score declines. These figures demonstrate the significance of creditbureau information to the bank-card industry, and of regulating this information, by showing that the regulation delivers significant credit access that was not available under full information. They also document an additional cost of filing bankruptcy, beyond the one-time offset of some assets against some debts documented previously. That is, consumers deciding whether to file bankruptcy are generally in bad circumstances, so they can expect weak future credit access whether or not they file. What the results here show is that, conditional on a consumer's circumstances, a bankruptcy flag has an additional limiting effect, implying an additional utility loss.

The big picture for the longer term is that creditworthiness declines. Ex-flag scores are lower, and debt and delinquency higher, than cumflag scores predict. That is, the net effect of the removal of bankruptcy information is that the past filers become riskier, as measured by scores, borrowing, and delinquency, than other consumers with the same initial scores, borrowing, and delinquency. There is also some 
evidence that this effect is stronger in states with higher exemptions, consistent with the "strategic" model of consumer creditworthiness supported by Fay, Hurst, and White (2002). Chapter 7 is filed about a million times a year, ${ }^{1}$ so the implication of these results is a large-scale distortion of credit access and increase in household financial risk.

The rest of the article is in five sections. Section II summarizes the relevant legislation and literature, Section III describes the data, Section IV measures the short-term effect, Section V measures the longerterm effect, and Section VI summarizes and concludes the article.

\section{Background}

\section{A. Relevant Legislation and Industrial Organization}

Two areas of legislation are relevant to the study of consumer credit after bankruptcy. Several aspects of personal-bankruptcy law have potentially important implications for postbankruptcy consumers and their creditors, as do some of the restrictions placed on credit bureaus. This section covers each briefly and discusses the adaptation of bankcard issuers to their legal environment.

Chapter 7 discharges existing debts, except those that cannot be discharged (e.g., student loans) and those that consumers reaffirm (e.g., car loans, so they can keep the cars). The discharge permanently enjoins the affected creditors from trying in any way to collect. In exchange, the consumer forfeits assets that exceed statutory exemptions, which vary by state. The alternative procedure is Chapter 13, where there is no forfeit or immediate discharge but instead a partial repayment on a 35 year schedule followed (if completed) by a discharge of the remainder. $^{2}$ This study focuses on Chapter 7 because it is the more common choice (about $70 \%$ of personal filings) and because the discharge simplifies the relation between the filing and future credit access. With the affected debt no longer outstanding, the subsequent importance of the filing to potential creditors is simply through the fact that it occurred, and when it occurred. Apart from the removal of bankruptcy information, there is no particular significance to the postbankruptcy year.

The legal schedule aside, more time since filing is intuitively better news about a consumer, in that it indicates distance from the circumstances that precipitated filing. Empirical research identifies medical expenditures and debt as strongly related to the filing decision (Sullivan 1968; Stanley and Girth 1971; Sullivan, Warren, and

1. According to a May 16, 2002, news release by the Administrative Office of the U.S. Courts, there were 1,036,410 nonbusiness Chapter 7 filings in the year that ended March 31, 2002.

2. For a detailed description of the different bankruptcy options, see Bankruptcy basics, available at www.uscourts.gov/publications.html. 
Westbrook 1989; and Domowitz and Sartain 1999), and since the underlying medical problem is fatal in some cases and cured in others, it is likely that its lingering influence on survivors declines over time. The influence of other bankruptcy-related events, such as job loss, business failure, or divorce, also decline. So an upward trend in credit access after bankruptcy makes sense from this perspective.

There is the potential for a countervailing force, however, in the law on repeat discharges. A filer is ineligible for a subsequent discharge until 6 years after a previous discharge; the discharge is the final event of the bankruptcy proceeding, so this means the filer cannot complete a second Chapter 7 filing until 6 years after completing the first. Therefore, recent Chapter 7 filers are different from the rest of the population in their delayed access to Chapter 7 as an escape from debt obligations. During the delay, impaired creditors may be able to garnishee wages or otherwise seize value, which means that the 6 year rule may boost the filer's creditworthiness, where this boost would decline to zero by 6 years. It would intuitively bottom out well before 6 years, since consumers' unsecured credit is generally bank cards, and the default-risk difference between a bank-card holder who can file in a few years and one who can file right away appears small. The one who can file in a few years could wait a while, charge his or her limit, maybe make a few minimum payments, and then file. So the likely path of creditworthiness after filing, given that the filing and its date are observable, is the sum of two trends: an upward trend due to generally changing circumstances and a downward trend that flattens some time before 6 years, due to the repeat-discharge law.

The law that governs whether the filing and its date are observable is the Fair Credit Reporting Act (FCRA). Ten years after the date of adjudication of bankruptcy, the date shortly after filing when the court decrees that the filer is bankrupt, the FCRA requires credit bureaus to exclude the filing from reports (FCRA sec. 605(a)(1)). So the moment that the credit bureau carries out this order, the report that potential creditors can observe loses all reference to the filing. The moratorium for all other adverse items is 7 years (FCRA sec. 605(a)(2-6)), so all derogatory information about a filer's prepetition debt is gone by 7 years postpetition. Neither this nor any other law obliges creditors not to condition on bankruptcies more than 10 years before or other delinquencies more than 7 years before; the obligation is only for "consumer reporting agencies" not to report this information to third parties. ${ }^{3}$

3. For example, it would appear to be legal for an issuer to deny credit on the basis of a 12 -year-old bankruptcy it had observed and recorded itself because one of its cards was involved. This would further appear to encourage issuers to merge, so as to condition their credit granting on more internal data, although conceivably the FCRA could apply to data acquired this way. 
In addition to restricting what credit reports contain, the FCRA also restricts the scenarios under which they may be furnished. The scenario important to the bank-card industry, the one responsible for the 3 billion per year "pre-approved" solicitations, ${ }^{4}$ is FCRA section 604(c)(1)(B), allowing bureaus to furnish reports "in connection with any credit or insurance transaction that is not initiated by the consumer," provided that "the transaction consists of a firm offer of credit or insurance," and also that the consumer has not expressly prohibited bureaus from doing this. A "firm offer of credit or insurance" is defined in FCRA section 603(1) as one where the consumer must be offered credit if the report meets "specific criteria" and if the information the consumer sends back to the creditor meets some additional limited standards. In this way, bank-card issuers actively seek out consumers with attractive credit reports, quickly bringing the consumers' bank-card access to their attention.

Credit reports show creditors a long list of statistics relating to credit use. Creditors are free to process these statistics as they see fit, but they can also refer to commercially provided credit scores. Credit scores map credit reports to scalar estimates of creditworthiness, and while several scores are available, the FICO score of Fair Isaac and Company is by far the most widely referenced. Over $75 \%$ of mortgage loans use FICO scores, ${ }^{5}$ corporate credit-rating agencies characterize the risk of consumer receivables in securitizations by reference to FICO scores, ${ }^{6}$ and underwriting standards often refer explicitly to FICO scores. ${ }^{7}$ So the FICO score is not only a respected estimate of a credit report's implied creditworthiness, it is the implied creditworthiness for some purposes.

\section{B. Relevant Literature}

With its exploration of credit access after Chapter 7, this study contributes to the growing literature on personal bankruptcy. The theoretical literature observes that the bankruptcy code balances the benefit of insuring against expensive misfortunes against the cost of facilitating creditor abuse (e.g., Rea 1984; Dye 1986; and Athreya 2001). One goal

4. "Banks expand card marketing and credit extension while seeking to restrict consumer access to bankruptcy," Consumer Federation of America July 8, 1998, press release. Note that this is about one card every 12 days for the average household.

5. "Borrower's rate may hinge on credit score," Boston Herald, November 23, 2001, p. 46.

6. For example, see "Fitch rates GMACM mortgage loan trust series 2001-J7," Fitch press release, November, 29, 2001.

7. For example, the October 31, 2001, press release, "NextCard retains Goldman Sachs to pursue sale of the company" from NextCard reads, in part, "the Company has further tightened its underwriting criteria to limit new account originations to FICO scores above 680 ..." Also, since the FICO score does not reference any of the prohibited categories enumerated by Regulation B of the Equal Credit Opportunity Act, which include (among other factors) race, color, religion, national origin, sex, age, and marital status, granting credit explicitly by FICO score defends issuers against accusations of discriminating on these factors. 
of the empirical literature is to establish where this balance is struck, with several studies taking the straightforward approach of quantifying the circumstances of those filing bankruptcy. Sullivan (1968), Stanley and Girth (1971), and Sullivan and colleagues (1989) all find substantial medical debt owed by bankrupts, and presumably discharged in bankruptcy, which indicates at least some amount of insurance benefit to bankruptcy. The incidence of abuse is harder to pin down. Culhane and White (1999) estimate much less repayment capacity among filers, and by implication much less evidence of abusive filing, than Barron and Staten (1997).

Another way to establish consumers' use of bankruptcy is to fit a model of the filing decision. Domowitz and Sartain (1999) fit a model that embeds the choice between Chapters 7 and 13, and consistent with the earlier studies, they find high medical expenses provoking bankruptcy. Among the circumstances they associate with choosing Chapter 7 over Chapter 13 are low income, unemployment, and again high medical expenses. Gross and Souleles (2002) address the time series trend in aggregate bankruptcy filings, which was strongly upward from 1994 to 1998, and find by fitting a model predicting bankruptcy from household risk characteristics that credit-card holders were 1\% more likely to file in 1997 than in 1995, controlling for household risk. The implication is a simultaneous decrease in the perceived downside from filing, where this downside could be embarrassment, that is, 'stigma,' or reduced access to postbankruptcy credit.

Staten (1993) directly addresses the role of postbankruptcy credit by documenting a significant fraction of recent filers with at least one new credit relationship - $16 \%$ by 1 year postpetition and $53 \%$ by 5 years - and arguing that consumer creditors suffer a coordination problem. All creditors presumably want consumers to expect little credit after Chapter 7, since their historical recovery rate in Chapter 7 is so low, ${ }^{8}$ but they may also view recent filers as attractive customers and hence grant them credit. From this perspective, the upward trend in filings results from the upward trend in subprime consumer lending. Ausubel (1997) and Ellis (1998) also connect increasingly aggressive subprime lending to the filing rate, but their argument is that the extra loans simply increase the number of high-debt households that benefit from filing.

\section{Data Description}

The data for this article are two large panel databases, which we call the Bankruptcy Panel and the Geographic Panel, of condensed credit reports. The panels are populated differently and provide somewhat 
different information. For this study, the Bankruptcy Panel is useful for its large population of past filers, and the Geographic Panel is useful for its higher frequency and information on state of residence and on the exact month of bankruptcy-flag removal.

The Bankruptcy Panel, which was constructed specifically for the study of postbankruptcy credit, tracks 64,353 consumers: 44,353 who had Chapter 7 filings on their credit records as of 7/94 (the "filers") and 20,000 who had no filings on their records then (the "contrast group"). The large number of filers and the time series of their credit statistics are a great advantage over previous studies of bankruptcy. Experian assembled the panel by first drawing a random sample of $1 \%$ of all 7/94 credit reports, then from that group choosing all consumers with reported Chapter 7 filings, and also 20,000 with no Chapter 7 filings. For each panelist, we have a FICO score and a condensed credit file, known as a STAGG (STatistical AGGregate) file, every 3 months from 7/94 to 4/96 and also 9/97. Panelists had to survive to 9/97 to be included. We have the discharge month of each filing but the petition month of only a few, so to be consistent, the tests in the rest of the article refer exclusively to discharge months. The Bankruptcy Panel has filing information only on 7/94 and not on subsequent dates, so we cannot observe the exact month of its removal.

If we knew the date of adjudication of each filing and if credit bureaus removed bankruptcy information exactly 10 years later, then we would know each panelist's removal date. But we have the discharge date, which is generally around 4 months postadjudication ${ }^{9}$ but varies and, in any case, our data provider removes the information slightly before the tenth-year requirement, as early as $91 / 2$ years. Taking these uncertainties into account, we assume simply that bankruptcy flags are on credit reports at 9 years postdischarge and off by 10 years. The earliest discharge date we observe on 7/94 is 11/84 and the last observation date is $9 / 97$, so we have some data up to 12 years 10 months postdischarge. Since 11/84 is 116 months before 7/94, we assume when we have to estimate which filers do or do not have bankruptcy flags on 4/96 that the filers without flags are those with discharge dates 117 or more months before, that is, 7/86 or earlier.

A STAGG file is a consumer's credit report aggregated across creditors within credit categories such as bank cards, auto loans, mortgages, and so on. The STAGG files of the Bankruptcy Panel contain 354 variables for each date, indicating current and recent credit usage and delinquency, as well as credit lines where applicable. Examples include "Total [sum] outstanding balance on all open bank card trades" and "Total number of bank card trades 120 or more days delinquent or derogatory," where a "trade" is a credit relationship and 
an "open trade" is an active credit relationship. The last observation date of the Bankruptcy Panel, 9/97, predates the more recent practice by some creditors of strategically withholding information on credit limits and usage. ${ }^{10}$

The FICO score is a proprietary, scalar function of credit reports. The Experian/Fair, Isaac Model User Guide describes it as predicting credit performance over the next 24 months, calibrated so that creditworthiness increases with the score. In our sample, it is available for about $90 \%$ of the observations, and when it is not, the missing-value code almost always indicates that account activity in the past 6 months has been insufficient to calculate a score. There is no direct interpretation of a score, beyond the increasing relation to creditworthiness; to allow some interpretation of score changes, we calculate the percentile of each score in the Bankruptcy Panel relative to the contemporaneous scores of the 20,000 panelists in the contrast group. That is, we map each score to its "FICO percentile," which is the percent of scores in the contrast group, on the same observation date, below that score.

The Geographic Panel provides monthly credit reports of 100,642 consumers from 3/97 to 3/00, 37 observations in all (519 have one or more missing reports). Aside from the frequency, there are several important differences from the Bankruptcy Panel. The data are generally more extensive; we have each panelist's state of residence each month, and bankruptcy information each month, which means we observe exactly when the information disappears. The panel sample is geographically stratified, oversampling underpopulated states. While this results in few observations of past filers (there were 2,092 panelists with Chapter 7 flags as of 3/97), it boosts power for measuring cross-state variation.

\section{Short-Run Effect of Information Removal}

When a credit report loses the fact that a consumer previously filed for bankruptcy, the effect on the consumers' apparent creditworthiness is intuitively positive. And as the creditworthiness indicated by the other facts on the report increases, the effect intuitively grows. That is, the news content of past defaults increases as the experience of current creditors improves. We begin this section by establishing the existence and the cross-sectional dynamics of the initial effect of flag removal on FICO scores; then we follow the consumers for a year to gauge the practical effect on credit access.

10. According to an Experian white paper, the credit bureau first noticed this shift in reporting policy in November 1997, when a large national issuer stopped reporting credit limit and high-balance information "due to concerns of competitors stealing accounts." "Issuers Holding Out On Credit Bureaus," Volume 14, No. 11, Card News, June 16, 1999. 


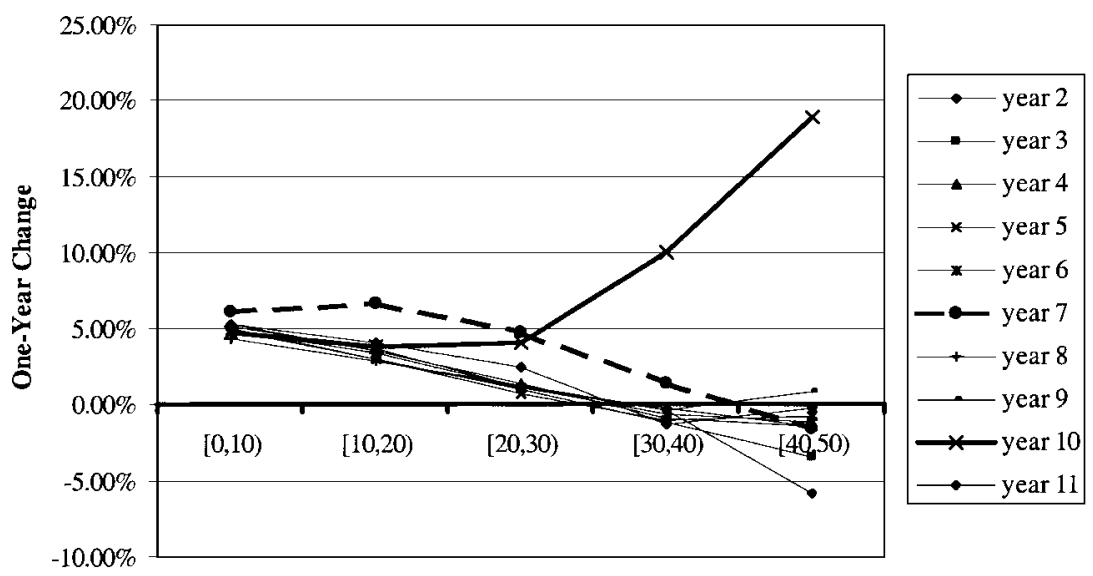

Percentile of Initial FICO

FIG. 1.-FICO-percentile change over the $y$ th postdischarge year

In the tests that follow, each filer in the Bankruptcy Panel provides exactly one observation of a 1-year change in credit statistics. Because the first four observations are quarterly, exactly one of the four dates is within a month (rounded off to the nearest month) of $y-1$ years after a filer's discharge month for 1 year $y$. For example, the first observation date 7/94 is within a month of 7 years postdischarge for those with discharges in June, July, or August 1987; and the second through fourth dates are not within a month of $y$ years postdischarge for these filers, for any $y$. Observations 5 through 8 are exactly 12 months after 1 through 4 , so for each filer, we observe the credit report at the beginning and end, approximately, of that person's $y$ th post discharge year for exactly one $y$. For convenience sake, these are referred to as the ends of the $y$ - first and $y$ th postdischarge years, but the dating is understood to be approximate.

\section{A. Bankruptcy and Credit Scores}

Let $F P_{c, y}$ be the FICO percentile, as defined previously, for consumer $c$ at the end of his or her $y$ th postdischarge year, so that $y$ th-year change is $F P_{c, y}-F P_{c, y-1}$. The empirical questions are whether this change is abnormally large for $y=10$, compared to other values of $y$ and whether it increases with $F_{c, y-1}$. We address both questions at the same time by first sorting consumers two ways, by $y$ into year groups 2 through 11 and by $F P_{c, y-1}$ into initial-score-percentile ranges $[0,10)$ through [40, $50)$, taking means within each year/score-range pair. ${ }^{11}$ The results are plotted as figure 1, which has initial score $F P_{c, y-1}$ on the horizontal axis and the 1-year FICO-percentile change $F P_{c, y}-F P_{c, y-1}$ on the

11. The small number of past filers with $S_{c, y-1}$ above 50, i.e., FICO scores above the contemporaneous median in the contrast group, are disregarded. 
vertical axis. Each line shows the score-percentile change as a function of the initial score percentile for a given postdischarge year.

The graph makes several points. First, FICO-percentile changes generally decline as the initial FICO percentile increases; in other words, FICO scores are mean-reverting. As Section V shows, that holds for consumers in general, not just bankrupts. Second, there is a small seventh-year effect that is stronger when the initial score is lower. Finally, there is a strong tenth-year effect for the best initial credits. FICO percentiles in the $40-50$ range at 9 years improve by 19 , implying that these consumers move ahead of $19 \%$ of the nonfiler population in apparent creditworthiness when their flags are removed. This is far above the usual change for scores in this range, which appears negative. The 10th-year effect decreases as $F P_{c, 9}$ decreases and is imperceptible for $0 \leq F P_{c, 9}<10$.

The 10th-year effect suggests that the 10-year reporting limit on bankruptcy information has a large effect on the perceived creditworthiness of borrowers, especially borrowers whose credit reports are otherwise positive. The 7th-year effect, and its shape, is consistent with the regulation of nonbankruptcy derogatory information. Over this year, the last details of the filing (charge-offs, repossessions, defaults, etc.) disappear, but the filing itself remains. This is good news for those whose details were relatively bad but not for those whose details were relatively good, so it fits that the 7th year boosts FICO percentiles for those with low initial scores but not high ones.

We establish the statistical significance of these patterns by regressing score changes on year dummies, along with a time trend, within each initial-score interval. Let $y_{c}$ be the postdischarge year observed for consumer $c$, and $I 7_{c}$ and $I 10_{c}$ be indicator variables for $y_{c}=7$ and $y_{c}=10$, respectively. We fit the model

$$
F P_{c, y}-F P_{c, y-1}=b_{0}+b_{1} y_{c}+b_{2} I 7_{c}+b_{3} I 10_{c}+\epsilon_{c}
$$

for each of the five ranges of $F P_{c, y-1}$. The results, collected in table 1, show a significantly positive 7th-year effect for all but the highest initial scores, and a significantly positive 10th-year effect for all but the lowest initial scores, thereby establishing the statistical significance of the results in figure 1. Reporting restrictions on adverse information deliver an immediate boost to apparent creditworthiness, as represented by FICO scores, especially that of the more-creditworthy past filers 10 years later. To see how this affects the clearing of the credit market, we move the analysis from scores to actual credit.

\section{B. New Credit after Flag Removal}

Does the effect of the flag-removal regulation on credit scores translate to meaningful changes in access to unsecured credit? A 
TABLE 1 Seventh and Tenth-Year Effects in Credit-Score Percentiles

\begin{tabular}{lccccc}
\hline Ex-ante Score & Intercept & Time Trend & $\begin{array}{c}\text { Seventh-Year } \\
\text { Effect }\end{array}$ & $\begin{array}{c}\text { Tenth-Year } \\
\text { Effect }\end{array}$ & $\begin{array}{c}\text { Number of } \\
\text { Observations }\end{array}$ \\
\hline$[0,10)$ & 5.56 & -.12 & 1.37 & .43 & 9,045 \\
& $<.01$ & $<.01$ & $<.01$ & 26.76 & \\
{$[10,20)$} & 3.85 & -.11 & 3.61 & 1.06 & 12,522 \\
& $<.01$ & .16 & $<.01$ & 2.23 & \\
{$[20,30)$} & 1.56 & -.07 & 3.66 & 3.18 & 9,523 \\
& $<.01$ & 10.10 & $<.01$ & $<.01$ & \\
{$[30,40)$} & -1.57 & .15 & 1.99 & 10.03 & 4,089 \\
& .21 & 4.49 & $<.01$ & $<.01$ & \\
{$[40,50)$} & -1.97 & .15 & -.66 & 19.28 & 1,297 \\
& 10.06 & 35.03 & 52.79 & $<.01$ & \\
& & & & &
\end{tabular}

NotE.-For each past filer $c$ in the Bankruptcy Panel, we observe the change in the credit score from the end of $y-1$ years postdischarge to the end of $y$ years, for exactly one $y$. Let $y_{c}$ be the $y$ for panelist $c$, and let $F P_{c, y}$ be the percentile, relative to the simultaneous distribution of the FICO scores of nonfilers in the Bankruptcy Panel, of $c$ 's FICO score at the end of $y$ years postdischarge. Panelists are sorted by $F P_{c, y-1}$ into five ranges $[0,10)$, for $S_{c, y-1}$ in $[0,10)$, also $[10,20),[20,30),[30,40)$, and $[40,50)$. Each pair of rows in this table represents a regression of the form $F P_{c, y}-F P_{c, y-1}=$ $b_{0}+b_{1} y_{c}+b_{2} I 7_{c}+b_{3} I 10_{c}+\epsilon_{c}$, where $I 7_{c}$ is a $1 / 0$ indicator for $y_{c}=7$, and $I 10_{c}$ is a $1 / 0$ indicator for $y_{c}=10$. So $b_{0}$ is the intercept, $b_{1}$ is the time trend, $b_{2}$ is the abnormal change for $y_{c}=7$ given the time trend, referred to as the "Seventh-Year Effect," and $b_{3}$ is the analogous "Tenth-Year Effect." Two-sided $p$-values, in percentage terms, are below the coefficients in italics.

straightforward way to find out is to fit a regression model similar to that of table 1 with the dependent variable changed to a measure of credit access. The credit reports offer many potential measures; we focus on the broadest measures of bank-card access, the number and aggregate credit limit of a consumer's open bank cards.

The regression model is the same as in table 1, except that $I 7$ is dropped and $I 11$, an indicator for the eleventh year, is added. We drop $I 7$ to focus on flag removal, and add $I 11$ because there might be a lag before the credit access that flag removal brings appears on credit reports. For new credit to appear, an issuer must notice a consumer's score, mail that person the offer, receive the acceptance, and report back to the credit bureau. Even if this process begins soon after the flag goes down, sometime in the middle of the 10th year, it may not finish before the end of that year, so the 10th-year effect could extend into an 11thyear effect. Filers are sorted by $F P_{c, y-1}$ into four ranges: [0, 16.67), or low score, $[16.67,33.33)$, or medium score, $[33.33,50)$, or high score, and no score, for those with missing values for $F P_{c, y-1} .{ }^{12}$ Of the panelists with $y=10,28.1 \%$ have a low score, $34.4 \%$ have a medium score, $23.3 \%$ have a high score, $12.7 \%$ have no score, and $1.5 \%$ have $F P_{c, 9} \geq 50$ and therefore excluded. Results are in panels A (Number of Open Cards) and B (Total Credit Limit of Open Cards) of table 2.

12. We partition $[0,50)$ three ways, rather than five, to reduce clutter in the graphs and tables; and we include no score to address concerns that focusing on panelists with scores somehow biases the tests. 
TABLE 2 Tenth and Eleventh-Year Effects on the Number and Credit Limit of Bank Cards

\begin{tabular}{|c|c|c|c|c|c|}
\hline Ex-ante Score & Intercept & Time Trend & $\begin{array}{l}\text { Tenth-Year } \\
\text { Effect }\end{array}$ & $\begin{array}{c}\text { Eleventh-Year } \\
\text { Effect }\end{array}$ & $\begin{array}{l}\text { Number of } \\
\text { Observations }\end{array}$ \\
\hline \multicolumn{6}{|l|}{ A. Number of cards: } \\
\hline \multirow[t]{2}{*}{ No score } & .04 & .02 & .09 & .11 & 5,602 \\
\hline & 2.68 & $<.01$ & .51 & 9.28 & \\
\hline \multirow[t]{2}{*}{ Low score } & .05 & .003 & -.01 & .06 & 18,498 \\
\hline & $<.01$ & 19.01 & 77.72 & 31.32 & \\
\hline \multirow[t]{2}{*}{ Medium score } & -.06 & .04 & .27 & .45 & 16,048 \\
\hline & $<.01$ & $<.01$ & $<.01$ & $<.01$ & \\
\hline \multirow[t]{2}{*}{ High score } & -.17 & .07 & .24 & .44 & 3,631 \\
\hline & .59 & $<.01$ & $<.01$ & .15 & \\
\hline \multicolumn{6}{|c|}{ B. Total limit on cards $(\$)$ : } \\
\hline No score & $\begin{array}{l}-28 \\
58.43\end{array}$ & $\stackrel{52}{<.01}$ & $\begin{array}{l}54 \\
60.18\end{array}$ & $\begin{array}{l}202 \\
34.51\end{array}$ & 5,602 \\
\hline Low score & $\begin{array}{l}28 \\
66.72\end{array}$ & $\begin{array}{l}38.40 \\
\quad .40\end{array}$ & $\begin{array}{l}40 \\
81.29\end{array}$ & $\begin{array}{l}361 \\
29.61\end{array}$ & 18,498 \\
\hline Medium score & $\begin{array}{l}-406 \\
<.01\end{array}$ & $\begin{array}{l}219 \\
<.01\end{array}$ & $\begin{array}{l}1,066 \\
<.01\end{array}$ & $\begin{array}{l}1,627 \\
<.01\end{array}$ & 16,048 \\
\hline High score & $\begin{array}{l}211 \\
58.66\end{array}$ & $\begin{array}{l}260.01 \\
.01\end{array}$ & $\begin{array}{r}1,796.01 \\
.01\end{array}$ & $\begin{array}{l}116 \\
89.05\end{array}$ & 3,631 \\
\hline
\end{tabular}

Note.-For each past filer $c$ in the Bankruptcy Panel, we observe the change in the credit score from the end of $y-1$ years postdischarge to the end of $y$ years, for exactly one $y$. Let $y_{c}$ be the $y$ for panelist $c$, and let $F P_{c, y}$ be the percentile, relative to the simultaneous distribution of the FICO scores of nonfilers in the Bankruptcy Panel, of $c$ 's FICO score at the end of $y$ years postdischarge. Panelists are sorted by $F P_{c, y-1}$ into four ranges: no score, for those with missing values for $F P_{c, y-1}$; low score, for those with $F P_{c, y-1}$ in $[0,16.67)$; medium score, for those with $F P_{c, y-1}$ in $[16.67,33.33)$; and high score, for those with $F P_{c, y-1}$ in $[33.33,50)$. Each pair of rows in this table represents a regression of the form $D_{c}=b_{0}+b_{1} y_{c}+b_{2} I 10_{c}+b_{3} I 11_{c}+\epsilon_{c}$, where $D_{c}$ is the $y_{c}-1$ to $y_{c}$ change in panelist $c$ 's number of bank cards (panel A) or aggregate credit limit on open bank cards (panel B, in dollars), $I 10_{c}$ is a $1 / 0$ indicator for $y_{c}=10$, and $I 11_{c}$ is a $1 / 0$ indicator for $y_{c}=11$. So $b_{0}$ is the intercept, $b_{1}$ is the time trend, $b_{2}$ is the abnormal change for $y_{c}=10$ given the time trend, referred to as the "Tenth-Year Effect," and $b_{2}$ is the analogous "Eleventh-Year Effect." Two-sided $p$-values, in percentage terms, are below the coefficients in italics.

For the past filers in the high score and categories, the 10th-year effect implies a substantial boost in credit access. In panel A, the point estimates for both groups are around one extra card per four consumers in the 10th year, and close to one per two consumers in the 11th. Similarly, in panel B, credit limits rise by over $\$ 1,000$ on average in the 10th year for both groups, and the medium score filers see a similar increase in the 11 th. ${ }^{13}$ There is little perceptible effect for filers with low or missing scores. These results demonstrate that the apparent increase in creditworthiness does affect actual allocation of credit. Lenders appear to depend on the scores, or similar functions of credit reports, and removing this information from reports affects their

13. A potential reason for the insignificant result for the high score panelists with $y=11$ is that there are only 60 such panelists. 


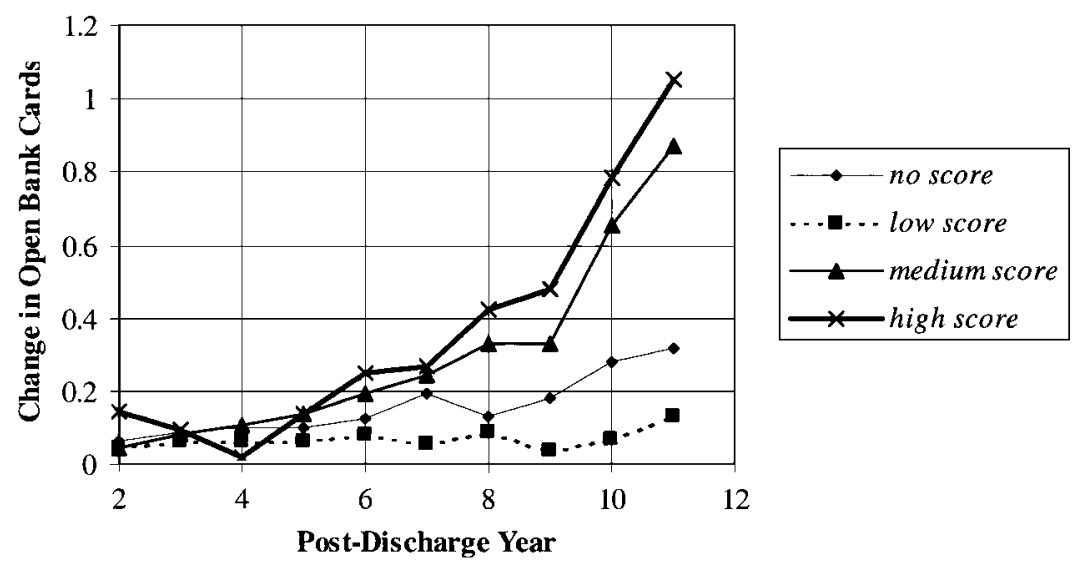

FIG. 2.-Change in number of open bank cards over $y$ th postdischarge year

decisions. The average changes for each initial-score/discharge-year combination are plotted as figures 2 (Number of Open Cards) and 3 (Total Credit Limit of Open Cards), where the postdischarge year is on the horizontal axis, the credit-access change is on the vertical axis, and there is one line for each initial-score range. Both graphs show little change for low- and missing-score consumers in each year, whereas for the higher-score consumers, there is a pronounced spike at year 10 . There is little perceptible trend around 6 years, which is consistent with the repeat-discharge moratorium having little effect, though - owing to the reasons outlined previously - the effect might be economically significant but too diffused across postdischarge years to detect.

These results from the Bankruptcy Panel show significant new credit access for the relatively more-creditworthy filers following the

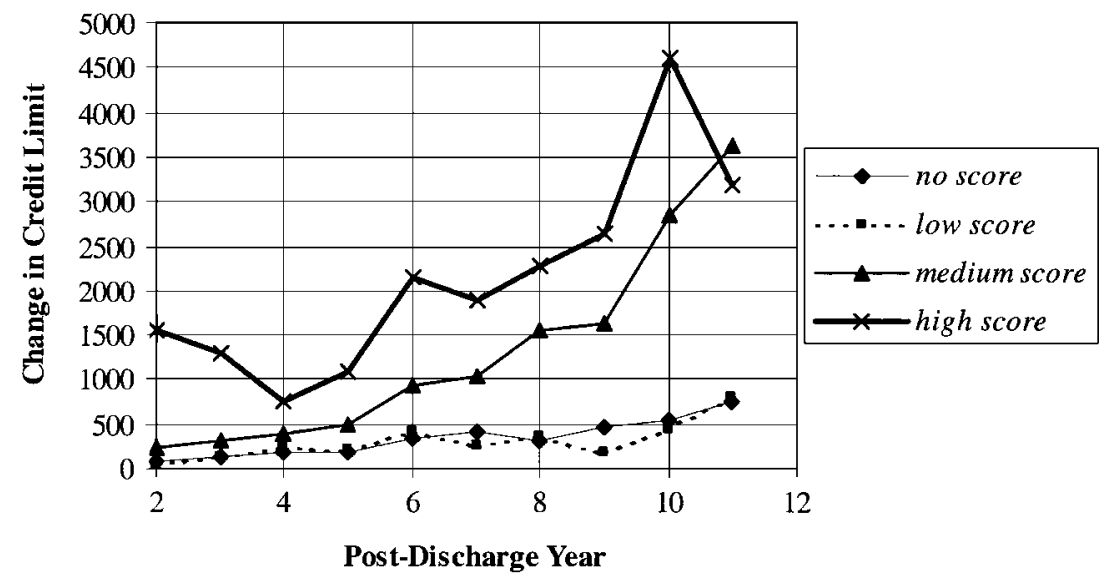

FIG. 3.-Change in credit limit of open bank cards over $y$ th postdischarge year (\$) 


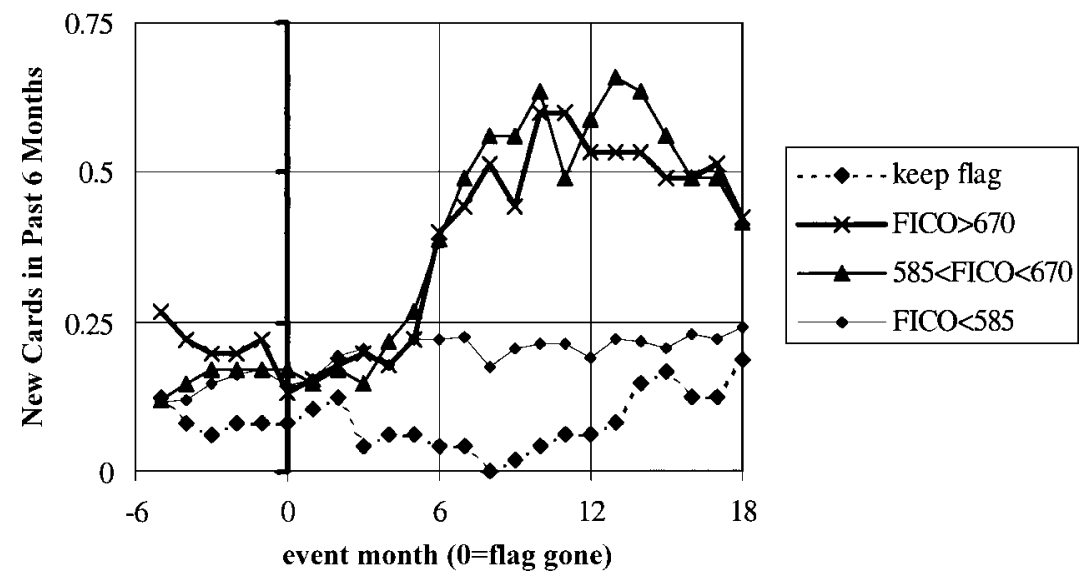

FIg. 4.-New bank cards in past 6 months, by months since flag removal (Geographic Panel).

flag removal. They cannot show the arrival of this credit in much detail, however, because the observations are quarterly and do not directly show the flag removal. By contrast, the Geographic Panel is monthly and does show the flag removal, so for panelists that lose flags, we know exactly when they lose them and can track their credit access over the months following. The cost of using the Geographic Panel is that the population of filers losing flags is small, and the data on credit limits are unreliable.

Our sample is all 134 panelists who lose Chapter 7 bankruptcy flags in 8/97 through 9/98, months 6 through 19 of our sample. This allows us to track their credit access from 5 months before to 18 months after the month they lose their flags, which we call month 0 . We sort them by their month -1 FICO scores into three groups, with cutoffs chosen to distribute the 134 panelists relatively evenly: the lower group, with scores below 585 (48 panelists), the middle group, with scores from 586 to 670 (45 panelists), and the upper group, with scores above 670 (41 panelists). We also track all the filers who do not lose their flags over the period (1,119 panelists), to reflect general trends. For this contrast group, month 0 is $6 / 98$. The statistic tracked is "Total number of bank cards opened within 6 months of the profile date," the broadest and highest-frequency measure of recent bank-card acquisition; the result, with one line per group, is plotted as figure 4 .

What figure 4 adds to figure 2 is that the new bank cards arrive soon after the regulatory event, arriving on reports in the second half of the first postflag year. The new, above-trend credit starts appearing on reports around 6 months post removal, and the 6-month measure appears to start trailing off around 12 months. 
This section shows that the 10th-year withdrawal of bankruptcy information from credit reports delivers an immediate boost in apparent creditworthiness for the filers with at least medium creditworthiness going into the year. It further shows that the boost translates to significant new credit access for these filers over the ensuing year. These results illustrate the efficacy of manipulating consumer credit by regulating credit bureaus. By the same token, they show that the filers received credit they would not have received under full information, which begs the question of whether this credit is too much. Excess credit implies excess household risk and delinquency, eventually; the remainder of the article addresses this question of whether this occurs by following filers' scores and delinquency as far into the postflag experience as the data allow.

\section{Longer-Run Effect of Information Removal}

The tests of tables 1 and 2 use the first eight observations of the Bankruptcy Panel. What we can do to track filers further past flag removal is follow them to the ninth observation, 17 months after the eighth. Because the Geographic Panel has 37 consecutive monthly observations and it reveals exactly the month that flags go down, we can collect its panelists who lose flags in its second through thirteenth months and track them to 24 months post flag. Because that panel also provides state of residence, we can sort these filers into those who would enjoy relatively higher and lower exemptions in a future default. Since exemptions shift credit risk to creditors, filers in higher-exemption states may exploit excess credit more aggressively and therefore exhibit relatively higher risk and delinquency. The first set of tests addresses FICO scores in the longer run and the second set addresses delinquency.

\section{A. Fico Scores in the Longer Run}

The empirical question is what happens to the scores after their initial rise. If the scoring algorithm makes efficient use of bankruptcy information, we would expect the ex-flag scores to return eventually to their cum-flag levels, as newly arriving information makes up for the information lost to the flag removal, if the consumers' true creditworthiness remained constant. However, excess credit suggests a decline in true creditworthiness, so that the net effect of the regulation may be that household risk is higher down the road than it was in the first place. In this case, we should find ex-flag scores to be abnormally low compared to cum-flag scores. To run a meaningful comparison we must account for the mean reversion, apparent in figure 1, that is a general feature of FICO scores.

Abusing slightly the notation of the previous section, let $F_{c, t}$ be the FICO score of consumer $c$ on observation date $t$. The mean 
TABLE 3 Longer-Run Scores and Delinquency in the Bankruptcy Panel

\begin{tabular}{|c|c|c|c|c|c|}
\hline Dependent Variable & Intercept & $F_{c, 7 / 94}$ & LOSEFLAG $_{c}$ & $Y_{c, 7 / 94}$ & $\begin{array}{l}\text { Number of } \\
\text { Observations }\end{array}$ \\
\hline \multicolumn{6}{|l|}{ A. OLS regressions: } \\
\hline$F_{c, 9 / 97}-F_{c, 7 / 94}$ & $\begin{array}{r}101.31 \\
<.01\end{array}$ & $\begin{array}{l}-.151 \\
<.01\end{array}$ & & & 15,212 \\
\hline$F_{c, 4 / 96}-F_{c, 7 / 94}$ & $\begin{array}{r}76.34 \\
<.01\end{array}$ & $\begin{array}{l}-.113 \\
<.01\end{array}$ & $\begin{array}{l}6.061 \\
<.01\end{array}$ & & 17,346 \\
\hline$F_{c, 9 / 97}-F_{c, 7 / 94}$ & $\begin{array}{r}102.26 \\
<.01\end{array}$ & $\begin{array}{l}-.152 \\
<.01\end{array}$ & $\begin{array}{c}-8.091 \\
<.01\end{array}$ & & 16,926 \\
\hline
\end{tabular}

B. Probit models:

\begin{tabular}{lccccc}
$D_{c, 4 / 96}$ & -2.191 & .005 & .059 & -.471 & 17,977 \\
& $<.01$ & $<.01$ & 17.02 & $<.01$ & \\
$D_{c, 9 / 97}$ & -2.279 & .005 & -.124 & -.166 & 17,664 \\
& $<.01$ & $<.01$ & .17 & .03 & \\
\hline
\end{tabular}

C. OLS regressions:

\begin{tabular}{|c|c|c|c|c|c|}
\hline$T_{c, 4 / 96}$ & $\begin{array}{r}-8,903 \\
1.06\end{array}$ & $\begin{array}{r}31.84 \\
<.01\end{array}$ & $\begin{array}{r}4,956 \quad 03 \\
.03\end{array}$ & $\begin{array}{r}.826 \\
<.01\end{array}$ & 17,977 \\
\hline$T_{c, 9 / 97}$ & $-8,252$ & $\begin{array}{r}44.80 \\
<01\end{array}$ & 8,208 & $\begin{array}{r}.804 \\
<01\end{array}$ & 17,664 \\
\hline$B_{c, 4 / 96}$ & $\begin{array}{c}-747 \\
27.12\end{array}$ & $\begin{array}{r}3.54 \\
.02\end{array}$ & $1,024.01$ & $\begin{array}{r}.795 \\
<.01\end{array}$ & 17,977 \\
\hline$B_{c, / 97}$ & $\begin{array}{r}-2,270 \\
.06\end{array}$ & $\begin{array}{l}7.17 \\
<.01\end{array}$ & $\begin{array}{r}1,887 \\
<.01\end{array}$ & $\begin{array}{r}.769 \\
<.01\end{array}$ & 17,664 \\
\hline$L_{c, 4 / 96}$ & $\begin{array}{r}-15,938 \\
<.01\end{array}$ & $\begin{array}{r}31.65 \\
<.01\end{array}$ & $\begin{array}{r}1,501 \\
.04\end{array}$ & $\begin{aligned} & .815 \\
&<<.01\end{aligned}$ & 17,977 \\
\hline$L_{c, 9 / 97}$ & $\begin{array}{r}-26,691 \\
<.01\end{array}$ & $\begin{array}{r}52.22 \\
<.01\end{array}$ & $\begin{array}{r}3,150 \\
<.01\end{array}$ & $\begin{array}{r}.860 \\
<.01\end{array}$ & 17,664 \\
\hline
\end{tabular}

Note.-The tests use two subsets of the Bankruptcy Panel: the 20,000 panelists with no Chapter 7 flags on their 7/94 credit reports, the "no-flag" panelists, and the 2,888 panelists that have Chapter 7 flags on their $7 / 94$ credit reports and discharge months between 11/84 and 7/86, the "lose-flag" panelists. The indicator variable $L O S E F L A G_{c}$ is 1 for the lose-flag panelists and 0 for the others, and the FICO score of panelist $c$ on date $t$ is $F_{c, t}$. The indicator variable $D_{c, t}$ is 1 if panelist $c$ is 30 or more days delinquent on an open trade on date $t$, and is otherwise 0 . The variables $T_{c, t}, B_{c, t}$ and $L_{c, t}$ are the total debt, bank-card debt, and bank-card credit limit, respectively, of panelist $c$ on date $t$, in dollars. Panel A reports ordinary least squares (OLS) regressions predicting score changes, where the first regression uses only no-flag panelists and the next two use both no-flag and lose-flag panelists. Panel B reports Probit models predicting delinquency, where a positive coefficient indicates that the probability of future delinquency decreases as the explanatory variable increases. Both Probit models use both noflag and lose-flag panelists. Panel C reports OLS regressions predicting total debt, bank-card debt, and bank-card credit limits, using the same panelists as panel B. For panels B and C, the column headed $Y_{c, 7 / 94}$ reports the coefficient on the 7/94 value of the dependent variable. Two-sided $p$-values are below the coefficients, in italics.

reversion is apparent if, using just the contrast group of nonfilers in the Bankruptcy Panel, we regress the change of FICO scores from the beginning to the end of the sample period, that is, $F_{c, 9 / 97}-F_{c, 7 / 94}$, on the initial score $F_{c, 7 / 94}$. This is the first regression in panel A of table 3 . The coefficient on $F_{c, 7 / 94}$ is significantly negative, consistent with mean reversion. To avoid confusing this predictable drift with the time series dynamics of interest, all the 
tests for FICO-score changes include the initial FICO as an additional regressor.

To establish the longer-run dynamics of FICO scores, we append to the contrast group those filers who lost their flags by 4/96. As explained in Section III, these are the filers with discharge months between $11 / 84$ and 7/86. The indicator variable LOSEFLAG $_{c}$ is 1 for these 2,888 panelists and 0 for the 20,000 contrast-group panelists. We run two regressions in which $F_{c, 7 / 94}$ and LOSEFLAG ${ }_{c}$ are the independent variables. In the first regression, the dependent variable is $F_{c, 4 / 96}-F_{c, 7 / 94}$, whereas in the second regression, it is $F_{c, 9 / 97}-$ $F_{c, 7 / 94}$. The first regression measures the excess change to an early date in the postflag experience, and the second regression measures the excess change to a later date. From table 1, we expect a positive loading on LOSEFLAG in the first regression, reflecting the initial rise; the loading in the second regression shows the longer-run effect. Results are in the second and third rows of table 3, panel A.

As expected, the excess FICO change of the flag-losing panelists to $4 / 96$ is positive. But tracking them down the road another 17 months, we find the opposite. Despite the intervening boost from the FCRA, the 9/97 scores of these panelists are significantly lower than their 7/94 scores predict. That is, the excess credit documented previously appears to lead to a long-run net increase in credit risk. For a better perspective on the timing of this reversal, we turn to the Geographic Panel, where we can track the panelists who lose their flags between 4/97 and 3/98 from exactly the month the flags disappear to exactly 24 months later. The downside is that there are only 96 such panelists. To these 96, we append, analogously to the preceding, all the nonfiler panelists, defined as those panelists without bankruptcy flags as of 12/97. For the 96 panelists who lose flags, we define month 0 to be the first month without a flag, and for the nonfiler panelists, we define month 0 to be $1 / 98$. We run five regressions that predict the change in FICO scores $0,6,12,18$, and 24 months after the flag removal, with the same explanatory variables from panel A of table 3: the cum-flag FICO score from month -1 , and the indicator LOSEFLAG for the flag-losing filers. The results are in panel A of table 4.

We find that the loading on LOSEFLAG turns from significantly positive in months 0 and 6 to significantly negative by month 18 . The 24-month loading is also negative, but the confidence interval is wide. Putting together these longer-run FICO score results, the boost in apparent creditworthiness delivered by flag removal is seen to be short lived, gone in a year and soon replaced by a score deficit. By this measure, removal of bankruptcy information increases the credit risk of the affected households.

While the credit-score reversal has direct implications for the households' ongoing access to credit, due to creditors' extensive 
TABLE 4 Longer-Run Scores and Delinquency in the Geographic Panel

\begin{tabular}{|c|c|c|c|c|c|c|c|}
\hline Dependent Variable & Intercept & $F_{c,-1}$ & LOSEFLAG $_{c}$ & $D_{c,-1}$ & $E_{c}$ & $E_{c} \times \operatorname{LOSEFLAG}_{c}$ & Number of Observations \\
\hline \multicolumn{8}{|l|}{ A. OLS regressions: } \\
\hline$F_{c, 0}-F_{c,-1}$ & $\begin{array}{l}10.05 \\
<.01\end{array}$ & $\begin{array}{l}-.015 \\
<.01\end{array}$ & $\begin{array}{l}9.72 \\
<.01\end{array}$ & & & & 88,428 \\
\hline$F_{c, 6}-F_{c,-1}$ & $\begin{array}{r}54.83 \\
<.01\end{array}$ & $\begin{array}{l}-.080 \\
<.01\end{array}$ & $\begin{array}{l}8.25 \\
2.20\end{array}$ & & & & 86,742 \\
\hline$F_{c, 12}-F_{c,-1}$ & $\begin{array}{r}90.89 \\
<.01\end{array}$ & $\begin{array}{l}-.134 \\
<.01\end{array}$ & $\begin{array}{r}-5.92 \\
17.32\end{array}$ & & & & 85,669 \\
\hline$F_{c, 18}-F_{c,--1}$ & $\begin{array}{r}108.84 \\
<.01\end{array}$ & $\begin{array}{l}-.161 \\
<.01\end{array}$ & $\begin{array}{r}-9.92 \\
4.03\end{array}$ & & & & 85,107 \\
\hline$F_{c, 24}-F_{c,-1}$ & $\begin{array}{r}107.46 \\
<.01\end{array}$ & $\begin{array}{l}-.160 \\
<.01\end{array}$ & $\begin{array}{r}-5.86 \\
26.49\end{array}$ & & & & 84,754 \\
\hline \multicolumn{8}{|l|}{ B. Probit: } \\
\hline$D_{c, 0}$ & $\begin{array}{l}.091 \\
33.01\end{array}$ & $\begin{aligned} & .004 \\
< & <.01\end{aligned}$ & $\begin{array}{l}-.122 \\
70.10\end{array}$ & $\begin{array}{r}-2.90 \\
<.01\end{array}$ & & & 88,428 \\
\hline$D_{c, 6}$ & $\begin{array}{c}-.218 \\
.07\end{array}$ & $\begin{aligned} & .003 \\
< & <.01\end{aligned}$ & $\begin{array}{l}.312 \\
29.37\end{array}$ & $\begin{array}{r}-1.28 \\
<.01\end{array}$ & & & 86,742 \\
\hline$D_{c, 12}$ & $\begin{array}{c}-.163 \\
.62\end{array}$ & $\begin{aligned} & .003 \\
< & .01\end{aligned}$ & $\begin{array}{l}.128 \\
59.27\end{array}$ & $\begin{array}{l}-.91 \\
<.01\end{array}$ & & & 85,669 \\
\hline$D_{c, 18}$ & $\begin{array}{l}-.016 \\
79.10\end{array}$ & $\begin{aligned} & .003 \\
< & <.01\end{aligned}$ & $\begin{array}{l}.062 \\
78.72\end{array}$ & $\begin{array}{l}-.67 \\
<.01\end{array}$ & & & 85,107 \\
\hline$D_{c, 24}$ & $\begin{array}{l}-.532 \\
<.01\end{array}$ & $\begin{array}{r}.003 \\
<.01\end{array}$ & $\begin{array}{l}-.283 \\
10.48\end{array}$ & $\begin{array}{l}-.38 \\
<.01\end{array}$ & & & 84,754 \\
\hline \multicolumn{8}{|l|}{ C. Probit: } \\
\hline $\begin{array}{l}D_{c, 0} \\
D_{c, 6}\end{array}$ & $\begin{array}{c}-1.295 \\
<.01 \\
-1.828 \\
<.01\end{array}$ & $\begin{array}{c}.005 \\
<.01 \\
.005 \\
<.01\end{array}$ & $\begin{array}{c}.099 \\
72.86 \\
.438 \\
11.32\end{array}$ & $\begin{array}{r}-2.32 \\
<.01 \\
-1.16 \\
<.01\end{array}$ & $\begin{array}{r}.021 \\
15.80 \\
-.01 \\
49.30\end{array}$ & $\begin{array}{c}.354 \\
50.03 \\
-.477 \\
20.55\end{array}$ & 86,742 \\
\hline
\end{tabular}


TABLE 4 (Continued)

\begin{tabular}{|c|c|c|c|c|c|c|c|}
\hline Dependent Variable & Intercept & $F_{c,-1}$ & LOSEFLAG $_{c}$ & $D_{c,-1}$ & $E_{c}$ & $E_{c} \times \operatorname{LOSEFLAG}_{c}$ & Number of Observations \\
\hline \multirow[t]{2}{*}{$D_{c, 12}$} & -1.911 & .005 & -.355 & -.84 & -.02 & .397 & 85,669 \\
\hline & $<.01$ & $<.01$ & 6.70 & $<.01$ & 12.63 & 20.52 & \\
\hline \multirow[t]{2}{*}{$D_{c, 18}$} & -1.736 & .005 & -.006 & -.62 & -.02 & -.217 & 85,107 \\
\hline & $<.01$ & $<.01$ & 97.77 & $<.01$ & 4.62 & 48.14 & \\
\hline \multirow[t]{2}{*}{$D_{c, 24}$} & -2.092 & .005 & .378 & -.45 & -.02 & -.629 & 84,754 \\
\hline & $<.01$ & $<.01$ & 11.95 & $<.01$ & 2.99 & 4.69 & \\
\hline
\end{tabular}

NoTE.-There are 96 panelists in the Geographic Panel who lose their Chapter 7 bankruptcy flags between 4/97 and 3/98. For panelist $c$ of these 96 , we set LOSEFLAG ${ }_{c}$ to 1 and define month 0 to be the first month without the flag and $F_{c, n}$ to be the FICO score $n$ months after month 0 , so that $F_{c,-1}$ is the FICO score in the last month with the flag. $D_{c, n}$ is 1 if panelist $c$ was 30 or more days delinquent on an open trade $n$ months after month 0 . Definitions are the same for all other panelists, except that, for them, month 0 is defined as $1 / 98$ and $\operatorname{LOSEFLAG}_{c}$ is set to 0 . For any panelist $c, E_{c}$ is 1 if $c$ resides in a state with exemptions at or above the median for state exemptions and is otherwise 0 . Panel A reports OLS regressions predicting score changes. Panels B and C report Probit models predicting delinquency, where a positive coefficient indicates that the probability of future delinquency decreases as the explanatory variable increases. Two-sided $p$-values are below the coefficients, in italics. 
reliance on FICO scores, they do not completely settle the question of whether the households actually become less truly creditworthy. This is because FICO scores automatically decline when consumers accept or inquire after credit. ${ }^{14}$ We need a more direct view of true credit risk, which we get by predicting actual delinquency. This is the task of the last group of tests.

\section{B. Delinquency in the Longer Run}

Is ex-flag delinquency more likely than cum-flag credit scores predict? That is, using the full-information scores from before the flag removal, what is the effect of the postremoval increase in credit on actual delinquency? To find out, we predict whether a consumer is delinquent on a post-flag-removal date, using three predictors: the cum-flag score, the lagged value of the same measure of delinquency, and the indicator for flag-losing filers. The empirical question is whether losing the flag leads to greater delinquency down the road.

We say that consumer $c$ is delinquent on date $t$ if the consumer has an open trade whose present status is 30 or more days delinquent. In that case, the value of $D_{c, t}$ is 1 ; otherwise it is 0 . The prediction model is a Probit, where the dependent variable is $D_{c, t}$ and the explanatory variables are the FICO score and the value of $D$ as of the initial date $7 / 94$ and the previous indicator LOSEFLAG. We fit this model for the sample used in the regressions of table 3, panel A, and report the results in table 3 , panel $\mathrm{B}$. The first model predicts delinquency as of $4 / 96$, and the second model predicts delinquency as of 9/97, both using 7/94 information. A positive loading means that the probability of delinquency goes down as the variable goes up.

The initial FICO scores come in significantly positive, as expected. Higher scores imply a lower probability of delinquency 21 and 38 months later. The lagged value of $D$ is significantly negative, which is also expected. There is no separate influence of LOSEFLAG as of $4 / 96$, but by $9 / 97$ it predicts extra delinquency. Controlling for a consumer's score and delinquency at 7/94, we find greater delinquency by $9 / 97$ if this person's bankruptcy information disappeared by $4 / 96$. That is, dropping the flag increases the longer-run incidence of delinquency. Running the analogous test on the Geographic Panel, reported in panel B of table 4 , we find that, after 2 years, LOSEFLAG relates to greater delinquency, with a $p$-value of $10.5 \%$.

Panel B of tables 3 and 4 show a greater incidence of delinquency among ex-flag consumers than cum-flag scores predict. The underlying cause suggested by tables 1 and 2 is that flag removal allows consumers to take down more credit than cum-flag scores predict. We can

14. See, e.g., "Credit rater eases multiple-inquiries penalty," Lexington Herald-Leader, January 23, 1998. 
test for this effect in the Bankruptcy Panel with regressions predicting ex-flag credit in 4/96 and 9/97 with the predictive variables from panel $\mathrm{B}$ of table 3: the FICO score and the lagged dependent variable in 7/94, and the indicator LOSEFLAG. The fitted value of LOSEFLAG shows ex-flag credit net of the credit predicted by cum-flag credit and scores. Three measures of credit are considered: total outstanding balance on all open trades, total outstanding balance on all open bank-card trades, and total credit limit on all open bank-card trades, denoted $T_{c, t}, B_{c, t}$, and $L_{c, t}$, respectively, for consumer $c$ on date $t$. Results are in panel C of table 3.

The predictive regressions show substantially more ex-flag borrowing than cum-flag scores and borrowing predict. Total borrowing is $\$ 4,956$ more in the short term, $\$ 8,208$ more in the longer term, and about a quarter of this extra borrowing is with bank cards. ${ }^{15}$ The extra bank-card borrowing is about two-thirds of the extra bank-card limit. So the excess probability that postflag consumers go delinquent coincides with an accumulation of excess debt, consistent with the latter causing the former.

The final test is for the influence of state exemptions. States with higher exemptions allow consumers to keep more property from creditors, so strategic consumers (in the sense of Fay et al. 2002) see more benefit from delinquency if they live in these states. Sorting consumers by their states' exemptions, we should expect to see the excess credit provoke relatively more delinquency among the highexemption filers. This would be consistent with the finding of Gropp, Scholz, and White (1997) that car-loan interest rates are higher for debtors in high-exemption states. Only the Geographic Panel indicates state of residence, so we can test for this effect only in its small sample.

The first step is to classify states as high- and low-exemption. For each state and the District of Columbia we add up the homestead and nonhomestead exemptions, catalogued by Gropp et al. (1997), using the federal exemption wherever it is higher. If consumer $c$ resides in a state at or above the median total exemption, the value of $E_{c}$ is set to one, and otherwise it is zero. We test whether the effect of flag removal on future delinquency is stronger in the higherexemption states by starting with the Probit model of panel B of table 4 , and adding as additional explanatory variables both $E_{c}$ and the interaction LOSEFLAG ${ }_{c} \times E_{c}$. The empirical question is whether the interaction enters negatively, that is, whether it predicts delinquency. The results are in panel $\mathrm{C}$ of table 4.

15. If we run the same regression with bank-card borrowing replaced by the balance on open car loans, the point estimates are $\$ 878$ and $\$ 1,199$ in excess borrowing as of 4/96 and $9 / 97$, respectively; and if we replace it by the balance on open real-estate loans the excess borrowing is $\$ 1,773$ and $\$ 3,491$ in $4 / 96$ and $9 / 97$, respectively. All are statistically significant at the $1 \%$ rejection level. 
The Probit model never finds LOSEFLAG to be significant by itself, but the interaction with the exemption level enters negatively at the latest date, 24 months post flag. ${ }^{16}$ While the sample is small and the potential for interference from other cross-state effects cannot be ruled out, this supports the strategic view of consumers' use of credit in which they impute their legal rights to keep value into their credit usage.

\section{Summary and Conclusion}

Federal law requires credit bureaus to stop reporting bankruptcies after 10 years. Past bankruptcies are useful, adverse information about creditworthiness, and the unsecured consumer-credit market depends on credit bureaus, so the law has the potential to alter the clearing of this market significantly. In large panel databases of credit reports, we find both a short-run and a longer-run effect. In the short run, we find significant increases in FICO scores, bank cards, and their credit limits, particularly those of the more creditworthy past filers, across the moment when bankruptcy information is removed. That is, the reporting limit artificially boosts the apparent creditworthiness of past filers. In the longer run, we find that the score increase dissipates in a year, and by 18 months post removal, the scores are lower than the initial scores, those calculated with the bankruptcy information, predict. We also find that the debt and delinquency of the affected consumers are higher than their initial debt and scores predict and the extra delinquency is greater in states with higher property exemptions from creditors.

Thus, the removal of the flag leads to excessive credit, increasing the eventual probability of default. This is concrete evidence that the flag regulation has real economic effects. This is market efficiency in reverse. Information limits matter because they distort market clearing, moving risk exposures away from their prevailing balance. This is a logical effect of the bankruptcy-information limit, although it may not be the only effect. The eventual removal of bankruptcy information may encourage filers in their early postfiling years to use their credit carefully, to prepare for the moment when the past filing disappears from their files and leaves an otherwise attractive track record. On the other hand, to the extent that financially distressed consumers expect this boon years later, their incentives to file today are greater. With so many Americans passing through personal bankruptcy, the significance of balancing these effects correctly is large, making it a promising area for future research.

16. Interestingly, the high-exemption indicator $E_{c}$ is significantly negative at 18 and 24 months, implying that - bankruptcy issues aside - consumers in higher-exemption states are generally more delinquent in the future, controlling for initial score and delinquency. 


\section{References}

Athreya, K. 2001. The growth of unsecured credit: Are we better off? Federal Reserve Bank of Richmond Economic Quarterly 87 (Summer): 11-33.

Ausubel, L. M. 1997. Credit card defaults, credit card profits and bankruptcy. American Bankruptcy Law Journal 71 (Spring): 249-70.

Barron, J. M., and M. E. Staten. 1997. Personal bankruptcy: A report on petitioners' ability to repay. Working paper, Purdue University and Georgetown University.

Culhane, M. B., and M. M. White. 1999. Taking the new consumer bankruptcy model for a test drive: Means-testing real Chapter 7 debtors. American Bankruptcy Institute Law Review 7 (Spring): 27-78.

Domowitz, I. and R. L. Sartain, 1999. Determinants of the consumer bankruptcy decision. Journal of Finance 54 (February): 403-20.

Dye, R. A. 1986. An economic analysis of bankruptcy statutes. Economic Inquiry 24 (July): 417-28.

Ellis, D. 1998. The effect of consumer interest rate deregulation on credit card volumes, charge-offs and the personal bankruptcy rate. Bank Trends 98, no. 5

Fay, S., E. Hurst, and M. J. White. 2002. The household bankruptcy decision. American Economic Review 92 (June): 706-18.

Gropp, R., J. K. Scholz, and M. J. White. 1997. Personal bankruptcy and credit supply and demand. Quarterly Journal of Economics 112 (February): 217-51.

Gross, D. B., and N. S. Souleles. 2002. An empirical analysis of personal bankruptcy and delinquency. Review of Financial Studies 15 (Spring): 319-47.

Rea, S. A. 1984. Arm-breaking, consumer credit, and personal bankruptcy. Economic Inquiry 22 (April): 188-208.

Stanley, D. T., and M. Girth. 1971. Bankruptcy: Problem, process and reform. Washington, DC: Brookings Institution.

Staten, M. E. 1993. The impact of post-bankruptcy credit on the number of personal bankruptcies. Credit Research Center Working Paper 58, Krannert Graduate School of Management, Purdue University.

Sullivan, G. 1968. The boom in going bust. New York: Macmillan.

Sullivan, T. A., E. Warren, and Jay L. Westbrook. 1989. As we forgive our debtors: Bankruptcy and consumer credit in America. New York: Oxford University Press.

White, M. J. 1987. Personal bankruptcy under the 1978 bankruptcy code: An economic analysis. Indiana Law Journal 63 (Fall): 1-57. 